\title{
STUDI EKSEGETIS MAKNA PASANGAN SEIMBANG DAN TIDAK SEIMBANG BERDASARKAN 2 KORINTUS 6:14-16
}

\author{
Sarwono \\ sarwono@sttab.ac.id
}

\begin{abstract}
A balanced life partner is very important because there are many different things that are found in the person of a believer and an unbeliever. God Himself establishes a suitable life partner that is not unbalanced. God knows that man His creation will need a balanced partner, therefore our partners are in God's hands, but very often when we choose an unbalanced life partner, we say that this is my partner from God, when in fact we are choosing by ourselves because there are some things that we pay attention to with our partners that can make us happy, we don't realize that it is only temporary, so we don't care anymore, whether it's balanced or not, what matters is my partner who is from God. Through this paper, we try to give a biblical explanation of a balanced and unbalanced partner to give insight to the believer in thinking about his life partner.
\end{abstract}

Keywords: Couples, Balanced.

Abstraksi: Pasangan hidup yang seimbang itu sangat penting karena ada banyak hal berbedaan yang terdapat dalam pribadi orang percaya dengan orang yang tidak percaya. Tuhan sendiri menetapkan pasangan hidup itu yang sepadan bukan yang tidak seimbang. Tuhan tahu bahwa manusia ciptaanNya akan memerlukan pasangan yang seimbang, sebab itu pasangan kita ada di tangan Tuhan, namun sering sekali ketika kita memilih pasangan hidup yang tidak seimbang, kita berkata bahwa ini pasangan saya yang dari Tuhan, padahal sesungguhnya kita yang sedang memilih sendiri oleh karena ada beberapa hal yang kita perhatikan dengan pasangan kita yang bisa membuat kita bahagia, kita tidak menyadari bahwa itu hanyalah sementara, sehingga kita tidak peduli lagi, mau yang seimbang atau tidak yang penting pasangan saya yang dari Tuhan. Melalui tulisan ini mencoba untuk memberikan penjelasan secara Alkitabiah mengenai pasangan seimbang dan tidak seimbang untuk memberikan wawasan kepada orang percaya dalam memikirkan pasangan hidupnya.

Kata Kunci: Pasangan, Seimbang. 


\section{LATAR BELAKANG SURAT 2 KORINTUS}

Surat Paulus yang kedua kepada jemaat di Korintus merupakan salah satu dari ketiga surat (1 dan 2 Korintus serta Roma) yang menepati posisi sentral dalam bagian Perjanjian Baru di Alkitab. ${ }^{1}$ Surat ini langsung ditulis oleh rasul Paulus yang mana Titus 2:13 adalah orang yang ditunjuk Paulus untuk mengantarkan surat ini, dengan harapan agar surat yang kedua juga disambut dengan baik oleh jemaat di Korintus. ${ }^{2}$ Paulus tiba di Korintus kira-kira pada musim gugur tahun 50. Ia mendirikan jemaat dan menetap disitu selama 18 bulan (Kis. 18:1-17). Kemudian ia pergi ke Efesus 18-19. Jemaat di Korintus terdiri dari beberapa orang Yahudi tetapi kebanyakan adalah orang bukan Yahudi yang dahulu menyembah berhala. Setelah Paulus meninggalkan Korintus, berbagai macam masalah timbul dalam gereja yang masih muda itu, yang memerlukan wewenang dan pengajaran rasulinya melalui surat-menyurat dan kunjungan pribadi.

Surat 2 Korintus merupakan lanjutan dari surat pertama yang juga ditujukan untuk jemaat di kota Korintus, Yunani. Surat ini langsung ditulis oleh rasul Paulus kira-kira 12 bulan sesudah surat 1 Korintus. ${ }^{3}$ Adapun urutan hubungan dan latar belakang penulisan 2 Korintus ini adalah sebagai berikut:

Pertama, setelah beberapa kali berhubungan antara Paulus dengan jemaat itu (misalnya: 1 Kor. 1:11; 5:9; 7:1), maka Paulus menulis 1 Korintus dari Efesus (awal tahun 55/56), kedua Paulus melakukan kunjungan di antara 1 dan 2 Korintus merupakan suatu kunjungan yang menyenangkan baik bagi Paulus maupun bagi jemaat itu (2:1-2), ketiga setelah kunjungan ini ada laporan disampaikan kepada Paulus di Efesus bahwa para penentang di Korintus itu masih menyerang pribadinya dan wewenang rasulinya. Keempat sebagai tanggapan terhadap laporan ini Paulus menulis 2 Korintus dari Makedonia (akhir tahun 55/56). Kelima Paulus mengadakan perjalanan ke Korintus dan tinggal di situ selama lebih kurang tiga bulan (Kis. 20:1-3a). Dari situlah ia menulis Kitab Roma. Kunjungan Paulus yang kedua kali di Korintus menyakiti hatinya. Dia menyebut tentang kunjungan ini di 2 Kor. 2:1. Dia memang sudah berencana untuk kembali ke Korintus (2 Kor. 1:15-2:1), tetapi tidak jadi. Akhirnya dia menulis surat dari Efesus kepada jemaat

\footnotetext{
${ }^{1}$ John Drance, Memahami Perjanjian Baru, (Jakarta: Gunung Mulia, 1996),346.

${ }^{2}$ J. Wesley Brill, Tafsiran Surat Korintus, (Bandung: Kalam Hidup, 2003), 10.

${ }^{3}$ Donald Guthrie, Tafsiran Alkitab Masa Kini 3 Matius-Wahyu, (Jakarta: Yayasan Komunikasi Bina Kasih/OMF, 1996),519.
} 
Korintus. Surat itu berisi teguran-teguran yang keras, tetapi ditulisnya dengan penuh kesedihan dan air mata (2 Kor. 2:4). ${ }^{4}$

Jadi Paulus berusaha untuk terus mengunjungi kota Korintus meskipun ada banyak yang menentang dia, mendengar laporan itu Paulus menulis suratnya dengan kesedihan dan air mata. Waktu penulisan ini bisa dikatakan ada dua kemungkinan antara 55-57 Masehi. Namun pendapat yang jauh berbeda dikemukakan oleh Donald Guthrie bahwa jarak penulisan antara 1 Korintus dan 2 Korintus tidak jauh berbeda, jika 1 Korintus ditulis antara tahun 55-57 maka 2 Korintus hanya terpaut tujuh bulan. ${ }^{5}$ Paulus menulis surat ini oleh Karena keadaan sulit yang dialami oleh jemaat Korintus serta pengaruhpengaruh yang menyesatkan jemaat Korintus. Selanjutnya dalam bukunya Stamp menuliskan:

"Paulus menulis surat ini kepada tiga golongan orang di Korintus yang pertama ia menulis untuk mendorong mayoritas dalam jemaat di Korintus yang tetap setia kepadanya sebagai bapa rohani mereka, yang kedua ia menulis untuk menantang dan menyingkapkan rasul-rasul palsu yang terus menerus berbicara menentang dia secara pribadi dengan harapan dapat meruntuhkan wibawa dan kerasulannya dan untuk memutar balikkan beritanya, yang ketiga ia juga menulis untuk menegur minoritas dalam jemaat yang sedang dipengaruhi oleh para lawan Paulus dan yang terus menerus menolak wewenang dan tegurannya. Paulus meneguhkan kembali integritas dan wewenang rasulinya, menjelaskan motivasinya dan memperingatkan mereka terhadap pemberontakkan yang lebih lanjut. ${ }^{6}$

Jadi surat 2 Korintus berfungsi untuk mempersiapkan jemaat secara keseluruhan untuk kunjungannya yang akan datang dan jemaat korintus tetap dalam kebenaran yang sudah mereka dengar serta untuk membantu jemaat yang ada di kota Korintus supaya tidak terpengaruh dengan ajaran-ajaran yang menyesatkan dan tetap semangat meskipun banyak kesulitan yang dialami.

Paulus mengakui bahwa orang Korintus tak dapat mengasingkan diri dari masyarakat (1 Kor. 5:9). Perkawinan campur tidak dapat dipatahkan, sekalipun orang Kristen harus tidak kawin dengan orang yang tidak percaya (1 Kor. 7:12; 7:39), maka

\footnotetext{
${ }^{4}$ Donald C. Stamps, Alkitab Penuntun (Malang: Gandum Mas, 2000), 1916

${ }^{5}$ Donald Guthrie, Pengantar Perjanjian Baru Vo. 2, (Surabaya: Momentum, 2009),49-50.

${ }^{6}$ Donald C. Stamps, Alkitab...,1917
} 
bersama dengan tetangga yang tidak percaya bukan hal yang tidak mungkin (1 Kor. 10:27). ${ }^{7}$ Sehingga Paulus melarang hubungan pribadi mereka dengan orang-orang yang tidak percaya oleh karena jemaat Korintus ini mudah sekali terpengaruh meskipun hal-hal yang mempengaruhi mereka adalah hal-hal yang tidak senonoh. Spittler dalam bukunya menuliskan bahwa:

Orang percaya yang sudah menikah dengan orang yang tidak percaya, tidak boleh diceraikan selama mereka mau hidup bersama-sama (1 Kor. 7:12,13). Anak-anak dari perkawinan semacam itu, berada dalam pengaruh Injil (7:14), yakni mereka dipengaruhi ke arah Allah dan kesucian. Lebih lanjut, suami atau istri yang tidak bertobat itu mungkin akan bertobat pada suatu waktu $(7: 16){ }^{8}$

Artinya bahwa orang yang sudah terlanjur menikah dengan orang yang tidak percaya, jangan diceraikan, melainkan orang yang sudah percaya harus mempengaruhi pasangannya yang belum percaya, sehingga pasangan itu juga mengenal Injil seperti dalam Kisah Para Rasul 6:1-2.

2 Korintus 6:1-10, di mana menyatakan ketidaktentraman hati Paulus karena kelakuan jemaat yang sering sekali berubah, dimana pada saat itu mereka menganggap biasa saja tentang apa yang disampikan oleh Paulus kepada mereka, sehingga Paulus mengungkapkan permohonannya dengan penuh kasih sebagai gembala sidang kepada jemaatnya, supaya mereka tidak menganggap remeh, melainkan melakukan dan meresponinya serta mereka tidak mudah dipengaruhi oleh ajaran-ajaran yang tidak berasal dari Allah. ${ }^{9}$ Jadi kelakuan orang Korintus sering sekali berubah karena pengaruh dari orang-orang yang berkunjung di daerah tersebut, itulah yang membuat hati Paulus sedih.

\section{KAJIAN EKSEGESE SURAT 2 KORINTUS 6:14-16}

\footnotetext{
${ }^{7}$ Donald Guthree, Tafsiran ...,550.

${ }^{8}$ Russell P. Spittler, Pertama ...,40.

${ }^{9}$ Russell P. Spittler, Pertama Dan Kedua Korintus, (Malang: Gandum Mas, 1977), 87.
} 
Pernikahan adalah satu komitmen seumur hidup antara seorang laki-laki dan seorang wanita yang melibatkan hak-hak seksual secara timbal balik. Hal ini jelas sejak semula Allah menciptakan "Laki-laki dan perempuan" (Kej. 1:27) dan memerintah mereka untuk "Beranakcucu dan bertambah banyak" (ayat 28). Pernikahan adalah satu kesatuan sosial dan spiritual. Pernikahan melibatkan satu perjanjian di hadapan Allah, bukan hanya satu kesatuan antara pria dan wanita yang melibatkan hak-hak perkawinan, tetapi merupakan satu kesatuan yang dilahirkan dari satu perjanjian dari janji-janji yang timbal balik. Komitmen ini tersirat dari sejak mulanya dalam konsep meninggalkan orangtua dan bersatu dengan isteri (Maleakhi 2:14). ${ }^{10}$

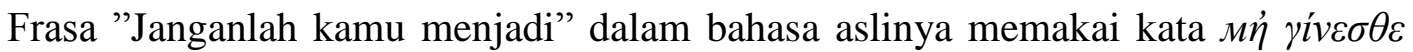
dari kata dasar $M \dot{\eta}$ yíve $\sigma \theta \varepsilon$ dalam bentuk kasus kata kerja imperative present bentuk kata ganti orang ke-2 jamak sekarang yang memiliki arti, sekali-kali tidak boleh, jangan menerima, menikah dengan. Jadi Tuhan memerintahkan orang percaya untuk tidak menerima atau menikah dengan orang yang tidak percaya kepada Kristus. ${ }^{11}$ Artinya bahwa orang yang sudah percaya kepada Kristus benar-benar dilarang berhubungan khusus terhadap orang-orang yang tidak percaya kepada Tuhan, tidak ada istilah mencobacoba, benar-benar dilarang dan tidak boleh kompromi dengan mereka yang tidak percaya.

Frasa "Pasangan yang tidak seimbang" dalam bahasa Yunani adalah

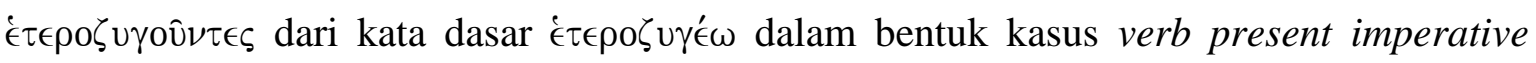
active nominative, jenis kelamin maskulin jamak, kasus ini menjelaskan kata kerja yang menjadi perintah ini menunjukkan bahwa tidak boleh coba-coba atau beranggapan nanti saya akan ajak jadi Kristen yang memiliki arti pasangan, kawan atau saudara yang tidak seimbang. Dalam New Internasional Version menggunakan kata be yoked together with unbelievers. ${ }^{12}$ yang artinya jadi janganlah memikul beban bersama-sama dengan tak beriman. Dalam Bahasa Indonesia Sehari-hari menuliskan janganlah menjadi sekutu orang-orang yang tidak percaya kepada Yesus. ${ }^{13}$ Dalam Firman Allah Yang Hidup

\footnotetext{
${ }^{10}$ Norman L. Geisler, Etika Kristen Pilihan Dan Isu, (Malang: Literatur SAAT, 2001),353-355.

11 Hasan Susanto, Perjanjian Interlinear Yunani-Indonesia Dan Konkordansi Perjanjian Baru (PBIK), (Jakarta: LAI, 2006),974.

${ }^{12}$ Ibid...,974.

${ }^{13}$ Ibid..,974.
} 
memakai kata terikat. ${ }^{14}$ Jadi pasangan tidak seimbang di sini tidak berbicara soal materi, melainkan iman kepercayaan kepada Kristus Yesus supaya orang percaya tidak terikat atau mengadakan persekutuan dengan orang-orang yang tidak percaya.

Perintah ini dapat diterjemahkan menjadi "hentikan kebiasaanmu menjadi terikat secara heterogen dengan orang-orang yang tidak percaya”. Prinsip ini mengacu balik kepada peraturan Musa (Im. 19:19; Ul. 22:10), orang-orang Kristen adalah "ciptaan baru" ( 2 Kor. 5:17), secara rohani mereka tidak boleh bersatu dengan orang-orang belum percaya yang mati secara rohani (Ef. 2:1). Istilah Methoce yang diterjemahkan dengan bersatu hanya terdapat dalam Perjanjian Baru artinya ialah berbagi, keterlibatan. ${ }^{15}$

Pasangan yang tidak seimbang ini berarti bahwa orang percaya harus terpisah dari yang jahat dan mengabdi pada pelayanan Allah artinya terpisah dari jahat yang ditunjukkan melalui cara hidup yang berbeda yang membuktikan tingkah laku moral yang sangat mulia. Pengabdian kepada Allah ditunjukkan melalui penolakkan terhadap semua campur tangan berhala. Berarti menjadi pasangan yang tidak seimbang sama saja menjadi satu hati dan pikiran dengan mereka, berkompromi dengan nilai-nilai mereka, terbujuk oleh komitmen mereka. ${ }^{16}$ Jadi orang percaya harus hidup sebagai anak-anak terang akan berbuahkan yang terang yaitu kebaikan, keadilan dan kebenaran (Ef. 5:8-9).

Tidak baik jika orang baik menikah dengan orang jahat dan tidak kudus, terlebih yang sifatnya tetap. Mereka akan menempuh jalan yang berbeda, dan hal itu akan mendatangkan masalah dan duka. Hubungan semacam itu, di mana pilihan ada di tangan kita, harus ditetapkan berdasarkan peraturan. "Adalah baik bagi anak-anak Allah untuk bersekutu dengan orang-orang yang serupa dengan mereka, karena kemungkinannya akan lebih berbahaya bahwa yang buruk akan merusakkan yang lebih baik daripada mengharapkan yang baik akan menolong yang buruk". ${ }^{17}$

Istilah "Pasangan yang tidak seimbang", ungkapan ini diterjemahkan dari kata yang berarti "bersatu kuk dengan orang/pihak yang jenisnya berbeda". Hal ini diumpakan sama seperti pada (Ul. 22:10). Orang Israel dilarang membajak dengan memasangkan seekor lembu dan seekor keledai bersama-sama. Teks tidak menyatakan dalam hal apa saja orang

\footnotetext{
${ }^{14}$ Oman Y.H. Firman Allah Yang Hidup, (Bandung: Kalam Hidup, 1975),271.

${ }^{15}$ Charles F. Pfeiffer dan Everett F. Harrison, The Wyclifee ...,683.

${ }^{16}$ Manfred T. Brauch, Ucapan Paulus Yang Sulit, (Malang: SAAT, 1996), 189-190.

${ }^{17}$ Matthew Henry, Tafsiran Surat Roma, 1 dan 2 Korintus, (Surabaya: Momentum, 2015), 900
} 
Kristen tidak boleh bersatu kuk bersama orang yang tidak percaya. Menerjemahkan hal ini menjadi sekutu atau bekerja sama ataupun janganlah bergabung dengan kelompok yang tidak seimbang dan janganlah mau menjadi teman sekerja dengan mereka, lebih kepada menjauhi atau meninggalkan. ${ }^{18}$ Artinya bahwa orang percaya tidak boleh bersatu dengan orang-orang yang tidak seimbang dengan mereka di dalam memikul apapun itu.

Artinya bahwa orang percaya jangan sampai terpengaruh dengan mereka yang tidak percaya kepada Kristus, sehingga dilarang bergaul dengan mereka yang tidak percaya kepada Tuhan, bila orang percaya tidak mampu menguasai diri. Selanjutnya hal tersebut ditegaskan oleh Pfitzner, yang menuliskan:

Dalam teks ini menunjukkan perintah agar tidak bersekutu dengan orang-orang yang tidak percaya. Perintah agar mereka tidak menjadi pasangan yang tidak seimbang dengan orang-orang yang tidak percaya tidaklah mungkin menjadi larangan bagi segala bentuk hubungan apapun dengan orang-orang yang tidak beriman Kristen. Tidak seimbang diartikan "dikenakan kuk dengan seseorang yang berbeda". Jangan ada kemitraan palsu, persekutuan, atau kesepakatan dengan non-Kristen. Mereka harus terpisah dari dosa, hubungan apapun dengan orang-orang yang tak percaya yang akan mengancam eksklusivisme (kecenderungan memisahkan diri) konfesi (pengakuan iman) Kristen dan kesucian kehidupan Kristen harus dijauhi. ${ }^{19}$

Jadi hal-hal yang merusak hubungan orang percaya dengan Tuhan lebih baik menjauhi hal itu demi menjaga kesucian hidup didalam Kristus. Selanjutnya Herman Ridderbors menuliskan:

"Peringatakan agar jangan menjadi pasangan yang tidak seimbang dengan orang yang tidak percaya (2 Kor. 6:14; Ef. 5:7) tidak berarti orang percaya dilarang berelasi dengan mereka yang tidak percaya, melainkan orang percaya jangan ikut serta dalam perbuatan-perbuatan jahat mereka (Ef. 5:11). Orang percaya dengan orang yang tidak percaya memikul kuk yang berbeda. Larangan Paulus adalah kesatuan yang membahayakan "kuk", prinsip hidup dan aturan hidup orang percaya dan tidak percaya, dalam hal ini orang percaya harus bersikap tidak kompromi dengan tidak menyatukan apa yang berasal dari Kristus dengan apa yang melawan aturan-Nya". ${ }^{20}$

${ }^{18}$ Roger L. Omanson dan John Ellington, Surat Paulus yang kedua kepada jemaat di Korintus, (Jakarta: LAI, 2013), 138

${ }^{19}$ V.C Pfitzener, Kekuatan Dalam Kelemahan Ulasan Surat 2 Korintus, (Jakarta: Gunung Mulia, 2011), 101-102.

${ }^{20}$ Herman Ridderbos, Paulus Pemikiran Utama Theologinya, (Surabaya: Momentum, 2008). 320. 
Jadi orang percaya di kota Korintus tidak boleh berkompromi terhadap apa yang melawan aturan dari Kristus. Artinya bahwa orang yang sudah percaya kepada Kristus, dilarang untuk ikut serta dalam perbuatan-perbuatan orang yang tidak percaya yang tidak sesuai dengan kehendak Tuhan. Selanjutnya hal tersebut ditegaskan oleh Matthew Henry, dalam bukunya yang menuliskan:

"Paulus memperingati jemaat Korintus supaya tidak bersetubuh dengan orang-orang yang tidak percaya. Mengadakan hubungan-hubungan yang sifatnya tetap. Tidak baik jika orang baik menikah dengan orang yang jahat dan tidak kudus. Mereka akan menempuh jalan yang berbeda, dan hal itu akan mendatangkan masalah dan duka". ${ }^{21}$

Jadi menurut Matthew Henry bergaul sehari-hari saja tidak boleh, apalagi menjadi pasangan yang tidak seimbang dalam bersahabat dan menjalin hubungan dengan orang yang bebal dan tidak percaya. Meskipun kita tidak bisa menghindar untuk melihat, mendengar dan berada bersama-sama dengan orang-orang semacam itu, tidak boleh dipilih untuk menjadi sahabat karib. Artinya bahwa daripada orang percaya terpengaruh dengan orang yang tidak percaya dalam melakukan hal-hal yang tidak menyenangkan hati Tuhan lebih baik sama sekali orang percaya tidak bergaul dengan orang yang tidak percaya. Pendapat yang sama juga dituliskan oleh Donald C. Stamp, yang menuliskan:

"Dalam pandangan Allah, umat manusia pada akhirnya digolongkan dalam dua kelompok yaitu mereka yang ada dalam Kristus dan mereka yang tidak ada dalam Kristus. Karena itu orang percaya jangan bermitra secara sukarela atau berhubungan intim dengan orang tidak percaya. Karena hubungan semacam itu dapat merusakkan hubungan mereka dengan Kristus. Ini meliputi kemitraan dalam dunia usaha, golongan rahasia, kencan, pernikahan, dan persahabatan karib". ${ }^{22}$

Jadi menurut Stamp seharusnya hubungan orang percaya dengan orang yang tidak percaya cukup sejauh yang diperlukan dalam kaitan sosial atau ekonomi, tidak menjurus kepada hubungan yang lebih intim yaitu kencan dan pernikahan.

Jadi dari hasil analisa di atas Tuhan memerintahkan orang percaya untuk memilih pasangan hidup yang seiman karena kalau di lihat dari sejarah bangsa Israel, mereka seringkali jatuh pada penyembahan berhala karena pasangan mereka yang tidak seiman, yaitu pasangan dari bangsa lain. Padahal Tuhan sudah berfirman agar mereka tidak

\footnotetext{
${ }^{21}$ Matthew Henry, Tafsiran Surat Roma, 1 dan 2 Korintus, (Surabaya: Momentum, 2015), 900

${ }^{22}$ Donald C. Stamp, Alkitab Penuntun..., 1927
} 
mengambil pasangan dari bangsa lain selain bangsa Israel agar mereka tidak turut menyembah allah-allah bangsa lain. Raja Salomo pun yang dikatakan sebagai orang yang paling bijak ternyata jatuh kedalam dosa penyembahan berhala pada akhir hidupnya (1 Raj. 11:1-13). Hubungan itu harus didasarkan dengan Tuhan Yesus Kristus.

\section{Frasa "Kebenaran Dengan Kedurhakaan"}

Kata "kebenaran" dalam bahasa Yunani adalah dikaiosu,nh dari kata dasar

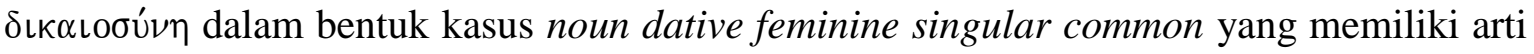
kebenaran, keadilan, ketentuan Allah, status atau hubungan yang benar dan pendermaan, ini menyatakan sifat atau karakter yang benar. ${ }^{23}$ Dalam New Internasional Version memakai kata righteousness artinya kebajikan. ${ }^{24}$ Dalam Bahasa Indonesia Sehari-hari memakai kata kebaikan. ${ }^{25}$ Kebenaran dalam kamus besar bahasa Indonesia adalah keadaan yang cocok, keadaan yang sesungguhnya, kejujuran, dan kelurusan hati. ${ }^{26}$ Dalam Living New Testament memakai kata don't love the Lord artinya yang tidak mencintai Raja. ${ }^{27}$ Dalam Firman Allah Yang Hidup memakai kata mengasihi Allah. ${ }^{28}$ Dalam Kamus Alkitab kebenaran adalah laporan-laporan yang telah diperiksa dan diuji secara pribadi ditetapkan sebagai benar dan terpercaya serta teruji. ${ }^{29}$ Jadi kebenaran itu orang-orang yang benarbenar mengasihi Allah serta telah teruji oleh karena pembenaran Yesus Kristus.

Kebenaran dalam tulisan Paulus menunjukkan kepada keadaan dibenarkan oleh (didamaikan dengan) Allah. Kata ini berarti tingkah laku yang benar atau melakukan hal yang benar (2 Kor. 3:9 dan 5:21). ${ }^{30}$ Mereka yang mempunyai karunia kebenaran Allah (5:21) tidak dapat hidup seperti mereka yang tidak mengetahui atau mengikuti kehendak Allah yang kudus (Rm. 6:19). Mereka harus menjauhkan diri dari hal-hal seperti zinah dan penyembahan berhala (1 Kor. $6: 18 ; 10: 14){ }^{31}$

\footnotetext{
${ }^{23}$ Hasan Susanto, Perjanjian Interlinear...,974.

${ }^{24}$ Ibid...,974

${ }^{25}$ Ibid..., 974

${ }^{26}$ Siswo Prayitno Hadi Podo, Kamus Besar Bahasa Indonesia Edisi Baru, 168

${ }^{27}$ Richard C. Halverson, The Living New Testament, (Jakarta: Tyndale House, 1967), 444

${ }^{28}$ Oman Y.H. Firman Allah Yang Hidup, 271

${ }^{29}$ W.R.F. Browning, Kamus Alkitab, (Jakarta: Gunung Mulia, 2011), 55

${ }^{30}$ Roger L. Omanson dan John Ellington, Surat Paulus yang kedua kepada jemaat di Korintus...., 139

${ }^{31}$ V.C. Pfetzner, Kekuatan Dalam Kelemahan, (Jakarta: Gunung Mulia, 2011),103.
} 
Kata "kedurhakaan" dalam bahasa Yunani adalah avnomi,a dari kata dasar $\alpha \nu o \mu i ́ \alpha$ dalam bentuk kasus noun dative feminine singular common yang memiliki arti kedurhakaan, pelanggaran hukum Allah dan kejahatan serta mental yang tidak mengindahkan hukum. Dalam New Internasional Version memakai kata wickedness adalah kejahatan. Dalam Bahasa Indonesia Sehari-hari kedurhakaan adalah kejahatan. ${ }^{32}$ Kedurhakaan ini juga dipakai di Matius 24:12; 2 Tesalonika 2:7 dan diterjemahkan menjadi "kefasikan" di Ibrani 1:9 "pelanggaran hukum" di Yohanes 3:4 kata ini mengandung arti dasar kejahatan atau pelanggaran terhadap hukum-hukum Allah. Kata ini sangat bertentangan dengan kebenaran baik di sini maupun di Roma 6:19. Kedua kata kebenaran dapat juga diterjemahkan menjadi orang yang benar dan orang yang jahat. ${ }^{33}$ Pendapat yang sama juga dituliskan Charles dalam bukunya bahwa:

"Kata anomia yang diterjemahkan menjadi kedurhakaan sesungguhnya berarti "liar tanpa hukum" (Ibr 1:9) kata persamaan seharusnya persekutuan karena terjemahan dari koinonia) maksudnya ialah "hubungan yang erat" seperti dalam ikatan pernikahan atau hubungan rohani dengan Allah (2 Kor. 13:14, 1 Kor. 1:9; 1 Yoh. 1:3, 6). Perbedaan antara terang dengan gelap terutama menonjol dalam tulisan-tulisan Perjanjian Baru (Yoh. 1:5; 3:19; Ef. 5:7, 11; Kol. 1:12, 13; 1 Yoh. 1:6). Kata persamaan (Symphonesis) hanya dipakai di sini di dalam seluruh Perjanjian Baru. Kekudusan dan kemurnian Kristus tidak mungkin selaras dengan kejahatan dan kenajisan Belial (sebuah sinonim untuk iblis). 1 Korintus 10:21 merupakan terjemahan yang tepat. Secara rohani keduanya tidak dapat bersama. Kata bagian yang merupakan terjemahan dari meris memberikan kesan adanya penggunaan bersama akan berbagai hal (Luk. 10:42; Kis. 8:21; Kol. 1:12). Kata hubungan (sunkatathesis) merupakan puncak dari empat kata sebelumnya yang dipakai Paulus untuk mengungkapkan persatuan penuh dosa antara anak-anak Allah dengan anak-anak iblis. Kata ini menunjukkan adanya kesatuan pikiran dan kehendak yang salin menghargai di dalam melaksanakan sebuah rencana yang telah disepakati bersama. ${ }^{34}$

Jadi artinya bahwa jangan sampai orang yang sudah hidup dalam kebenaran terpengaruh dengan orang yang melanggar hukum-hukum Allah.

Orang percaya mencemarkan kebenaran hanya dengan hubungan orang percaya yang tidak bisa dikendalikan, hanya karena hawa nafsu yang memuaskan diri saja,

\footnotetext{
${ }^{32}$ Hasan Susanto, Perjanjian ...,974.

${ }^{33}$ Roger L. Omanson dan John Ellington, Surat...,139.

${ }^{34}$ Charles F. Pfeiffer dan Everett F. Harrison, The Wyclifee...,683.
} 
sehingga orang percaya rela meninggalkan hidup orang percaya yang benar dan hidup dalam kedurhakaan, jadi kebenaran dan kedurhakaan tidak boleh disatukan ( $\mathrm{Rm}$ 6:19). ${ }^{35}$ Kedurhakaan ini menujukkan kepada orang-orang yang tidak taat kepada Tuhan, yang melakukan kejahatan atau tidak takut akan Tuhan, jadi orang yang sudah percaya kepada Kristus jangan ia menikah dengan orang yang tidak percaya kepada Tuhan Yesus, karena apabila demikan terjadi, maka keluarga tidak akan merasakan kebahagiaan dalam rumah tangganya, bisa terjadi rumah tangga tersebut akan kacau (Ul. 7:3-4; Ez. 10:10-12). Jadi seharusnya orang yang sudah tahu kebenaran, janganlah ia melakukan sesuatu yang tidak benar di mata Tuhan.

\section{Frasa "Terang Dengan Gelap"}

Kata "terang" dalam bahasa Yunani adalah $\varphi \omega \tau i ́$ dari kata dasar $\phi \hat{\omega} \varsigma$ dalam bentuk kasus noun nominative singular datif yang merupakan kata benda ganti orang pertama tunggal yang menjadi pelengkap secara tidak langsung yang memiliki arti suluh, terang dan cahaya. Dalam New Internasional Version memakai kata light artinya cahaya. Dalam Bahasa Indonesia sehari-hari memakai kata terang. ${ }^{36}$ Dalam Kamus Alkitab terang adalah suatu simbol yang sangat kuat untuk kebaikan dan kebenaran yang disebut pada awal (Kej. 1:3) dan pada akhir (Why. 22:5). ${ }^{37}$

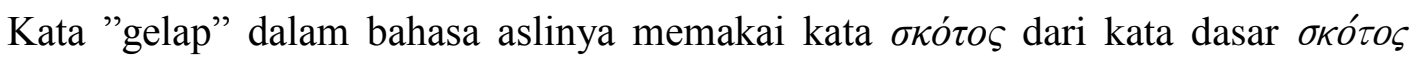
dalam bentuk kasus noun accusative neuter singular common yang memiliki arti kekelaman, gelap dan kegelapan. Dalam New Internasional Version memakai kata darkness artinya kegelapan. Dalam Bahasa Indonesia Sehari-hari memakai kata gelap. ${ }^{38}$ Jadi kegelapan yang dimaksud di sini ialah orang yang masih hidup dalam hal-hal yang buruk atau jahat.

Terang dan gelap menjelaskan sama seperti kebenaran dan kedurhakaan, kedua kata ini juga mengungkapkan dua hal yang berlawanan. Gelap dan terang digunakan 139.

${ }^{35}$ Roger L. Omanson dan John Ellington, Surat Paulus yang kedua kepada jemaat di Korintus...,

${ }^{36}$ Ibid...,974.

${ }^{37}$ W.R.F. Browning, Kamus Alkitab ...,444.

${ }^{38}$ Ibid...,974. 
sebagai lambang untuk menunjukkan sikap baik-buruk, atau percaya dan tidak percaya (Rm. 13:12; Ef. 5:11-14; 1 Tes. 5:5). ${ }^{39}$

Terang di sini menyatakan kebaikan seseorang, menjadi berkat bagi orang lain, mampu membawa orang lain ke jalan yang benar, sebab itu dikatakan jangan berhubungan dengan mereka yang hidup dalam kegelapan. Tidak masalah bila orang percaya bisa menjadi terang bagi orang yang tidak percaya, atau mampu membawa mereka kepada Kristus, tetapi bila malah orang yang hidup dalam terang meninggalkan terang itu dan mengikuti kegelapan, maka lebih baik orang percaya tidak perlu berhubungan dengan mereka yang hidup dalam kegelapan seperti dalam 1 Korintus 15:33 mengatakan "pergaulan yang buruk merusak kebiasaan yang baik", persekutuan Roh Kudus menolak persekutuan dengan orang-orang yang tidak percaya (Ef. 6:6-13; Rm. 13:12; 2 Kor. 4:6; 1 Tes. 5:5). ${ }^{40}$ Jadi orang percaya harus benar-benar menjadi terang atau menjadi berkat orang yang belum mengenal Kristus melalui kehidupan sehari-hari.

\section{Frasa "Kristus Dengan Belial"}

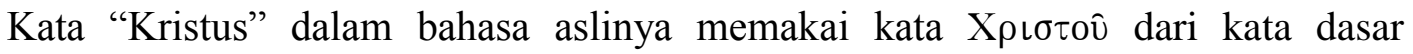
X Mesias dan diurapi. Dalam New Internasional Version memakai kata Christ artinya Kristus. Dalam Bahasa Indonesia Sehari-hari memakai kata Kristus. ${ }^{41}$

Kata "Belial" dalam bahasa Yunani adalah $B \in \lambda \iota \alpha \dot{\alpha} \rho$ dari kata dasar $B \in \lambda\llcorner\alpha \dot{\alpha} \rho$ dalam bentuk kasus noun accusative masculine singular yang memiliki arti Belial, nama setan atau antikristus. Dalam New Internasional Version memakai kata yang sama yaitu $\mathrm{B} \in \lambda\llcorner\alpha \lambda$. Dalam Bahasa Indonesia Sehari-hari memakai kata iblis. ${ }^{42}$ Dalam Living New Testament adalah devil artinya setan. $^{43}$ Belial dalam Perjanjian Lama menunjuk pada

${ }^{39}$ Roger L. Omanson dan John Ellington, Surat Paulus yang kedua kepada jemaat di Korintus..,

${ }^{40}$ V.C. Pfitzner, Kekuatan Dalam Kelemahan..., 103.

${ }^{41}$ Ibid..., 974

${ }^{42}$ Ibid..., 974

${ }^{43}$ Living New Testament 
ketidakberhargaan, bajingan, gulungan laut mati, penjahat dan dalam Perjanjian Baru menjadi sinonim untuk iblis (2 Kor. 6:15). ${ }^{44}$

Kristus dengan Belial tidak dapat satu, nama Belial untuk setan pada zaman Yahudi khususnya naskah laut mati. Sebab itu Anak Allah tidak dapat bersatu dengan lawan Allah, begitu juga orang percaya tidak dapat bersama-sama dengan orang yang tidak percaya dalam pengertian ikut serta dalam cara hidup orang tersebut atau ikut serta dalam sistem imannya. ${ }^{45}$ Kristus adalah kudus dan hidup (Im. 19:2; 1 Ptr. 1:16), sedangkan belial adalah setan. Kristus yang membawa kepada keselamatan, kebenaran dan menuntun jalan yang benar, sedangkan setan adalah roh yang hanya melakukan hal-hal yang buruk, yang membawa setiap orang ke jurang (Kej. 3:1-5) dan bisa meninggalkan Tuhan. Sebab itu dikatakan Kristus dengan Belial tidak dapat disatukan. Jadi orang percayapun juga tidak boleh berhubungan dengan orang tidak memuliakan Tuhan.

Jadi orang yang sudah mengenal Kristus harus mampu menunjukkan karakter Kristus dalam kehidupannya sehari-hari dan tidak lagi dipengaruhi oleh kuasa-kuasa yang tidak berasal dari Kristus. Orang yang sudah hidup di dalam Tuhan mampu menolak kuasa iblis dengan nama Kristus bukan terlibat dengan hal-hal yang menyakiti hati Tuhan.

\section{Frasa "Percaya Dengan Tidak Percaya"}

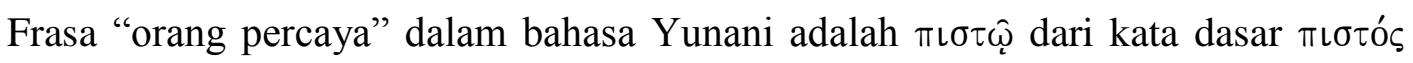
dalam bentuk kasus adjective normal dative masculine singular no degree kata sifat kasus datif normal yang maskulin dalam bentuk tunggal tidak (ada) derajat tingkat yang memiliki arti orang benar, orang percaya, orang beriman dan orang setia. Dalam New Internasional Version memakai kata believer artinya yang percaya. Dalam Bahasa Indonesia Sehari-hari memakai kata orang Kristen. ${ }^{46}$ Percaya di sini ialah orang yang melakukan yang benar, memiliki iman kepada Yesus Kristus serta tetap setia kepada Tuhan kepada Yesus Kristus yang menjadi Juruselamatnya.

Frasa "tak percaya" dalam bahasa Yunani adalah $2 \pi i \sigma \tau o \iota \varsigma \cdot$ dari kata dasar $\ddot{\alpha} \pi \iota \sigma \tau o \varsigma$ dalam bentuk kasus adjective normal dative masculine plural no degree kata sifat kasus datif normal yang maskulin jamak tidak (ada) derajat tingkat artinya menganggap

\footnotetext{
${ }^{44}$ W.R.F. Browning, Kamus Alkitab..., 54.

${ }^{45}$ V.C. Kekuatan..., 103

${ }^{46}$ Ibid....., 974
} 
mustahil, tak percaya, tidak beriman, tidak setia. Dalam New Internasional Version memakai kata unbeliever artinya tak beriman. Dalam Bahasa Indonesia Sehari-hari memakai kata bukan Kristen. ${ }^{47}$

Frasa "Orang-orang yang tidak percaya" menunjuk kepada orang bukan Kristen karena Paulus sedang memohon supaya orang Korintus berdamai dengannya. Dia mungkin menunjuk kepada para lawannya di dalam gereja di Korintus. Mereka adalah orang-orang yang menolak wewenangnya sebagai rasul. Di daerah-daerah tertentu supaya jelas maksudnya adalah orang bukan Kristen, maka istilah ini harus dilengkapi menjadi orangorang yang tidak percaya kepada Kristus. ${ }^{48}$

Jadi orang yang sudah percaya kepada Kristus tidak boleh bersatu dengan orang yang belum percaya karena mereka yang sudah percaya kepada Kristus akan melakukan hal-hal yang hanya memuliakan Tuhan dan ketika mereka berhubungan dengan orang yang tidak percaya, maka akan terjadi hal-hal yang tidak diharapkan dalam keluarga tersebut seperti kekerasan dalam rumah tangga, tidak akan terbina rumah tangga yang diharapkan Tuhan (Ef. 6:4) dan orang yang percaya kepada Kristus bisa juga akan meninggalkan atau melalaikan kegiatan kerohanian yang biasa ia lakukan demi keluarganya yang belum parcaya kepada Tuhan. Dampak bagi anak-anak yang sudah Tuhan percayakan sangat besar sekali karena akan-anak akan menjadi terombang ambing, tidak terdidik di dalam Kristus, anak akan menjadi bingung ikut dengan siapa dan bisa jadi anak akan menganggap agama itu tidak terlalu penting serta tidak akan menghargai orangtuanya sendiri.

\section{Frasa "Bait Allah Dengan Berhala"}

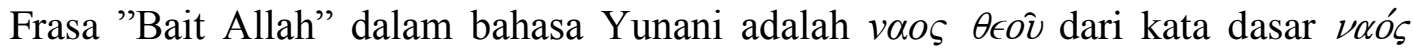
$\theta \epsilon o ́ \varsigma$ dalam bentuk kasus noun dative masculine singular common artinya bait Suci, bait Allah, bait kudus. Dalam New Internasional Version memakai kata temple of God artinya kuil untuk Tuhan "Bangunan tempat memuja atau penyembahan dewa. Dalam Bahasa Indonesia Sehari-hari memakai kata rumah Tuhan. ${ }^{49}$ Bait Allah adalah pusat tempat

\footnotetext{
${ }^{47}$ Ibid....., 974

${ }^{48}$ Roger L. Omanson dan John Ellington, Surat...,138.

${ }^{49}$ Ibid...,974.
} 
beribadah. Rencana suatu tempat tetap untuk peribadahan nasional di Yerusalem di pastikan oleh Daud dan diwujudkan oleh putranya Salomo (2 Sam. 24:18; 1 Raj. 6:7). ${ }^{50}$

Ayat 16 mengacu kepada sejumlah teks Perjanjian Lama "Aku akan menempatkan Kemah Suci-Ku di tengah-tengahmu (Im. 25:11-12; Yeh. 37:27). Paulus menafsirkan janji Allah untuk tinggal di antara umatNya (Kel. 25:8; 29:25) sebagai janji bahwa Ia akan tinggal bersama-sama dengan mereka sebagai baitNya. Tempat tinggal yang kudus berarti suatu umat yang kudus. ${ }^{51}$ Setiap orang percaya adalah bait Allah, sebab itu dikatakan bait Allah dengan berhala tidak dapat disatukan, sebab itu orang percaya tidak mungkin bisa bersama-sama dengan orang yang tidak percaya karena penyembahan kepada Allah dan dengan berhala yang mati sangat berbeda. Karena tidak mungkin pasangan itu bisa baik, bila berbeda kepercayaan.

Bait dari Allah (naos) yang dimaksudkan adalah tempat suci dalam batin (1 Kor. 3:16; 6:19). Pada masa-masa murtad, kejahatan dilakukan di tempat suci (2 Raj. 21:7; 23:6; Yeh. 6:3-18). Kuil orang kafir di Korintus merupakan kolam kejahatan (Rm. 1:1832). Imamat 26:11; Yehezkiel 37:27. Orang percaya harus memperhatikan bagaimana Paulus menopang perintahnya ( 2 Kor. 6:16a) dengan mengacu kepada lima pertanyaan yang sudah jelas jawabannya, dengan mengacu kepada Allah dan dengan mengacu kepada Alkitab. ${ }^{52}$ Jadi bait Allah bukanlah gedung, melainkan tubuh orang percaya yang telah dikuduskan dan disucikan.

Kata "berhala" dalam bahasa Yunani adalah $\epsilon \dot{\ell} \delta \omega \hat{\lambda} \omega \nu$; dari kata dasar $\epsilon " l \delta \omega \lambda o \nu$ dalam bentuk kasus noun genitive neuter plural common yang memiliki arti berhala, dewa. Dalam New Internasional Version memakai kata idols artinya berhala. Dalam Bahasa Indonesia Sehari-hari memakai kata rumah berhala. ${ }^{53}$ Istilah berhala menunjuk kepada dewa-dewa yang disembah oleh orang yang tidak mengenal Allah yang menggunakan istilah rumah berhala supaya sejajar dengan bait Allah. ${ }^{54}$

\footnotetext{
${ }^{50}$ W.R.F. Kamus Alkitab..., 43

${ }^{51}$ V.C. Pfetzner, Kekuatan Dalam Kelemahan...., 104.

${ }^{52}$ Charles F. Pfeiffer dan Everett F. Harrison, The Wyclifee Bible Commnetary, (Malang: Gandum Mas, 2001), 683

${ }^{53}$ Hasan Susanto, Perjanjian Interlinear...,974.

${ }^{54}$ Roger L. Omanson dan John Ellington, Surat...,141.
} 
Paulus menyajikan suatu argumentasi yang kuat bahwa seorang percaya yang sudah lahir baru, sebagai bait Allah dan Roh Kudus tidak dapat dirasuk roh jahat. Berhala melambangkan roh-roh jahat, karena itu bentuk kenajisan yang paling buruk dalam Perjanjian Lama adalah mendirikan berhala dalam bait Allah sendiri (2 Raj. 21:7, 11-14), begitu pula kita sama sekali tidak boleh menajiskan tubuh kita yang merupakan tempat kediaman Roh itu. Walaupun roh jahat tidak dapat hidup berdampingan dengan Roh Kudus dalam diri orang percaya yang sejati. ${ }^{55}$ Namun ketika seseorang itu belum hidup baru, masih dalam proses pertobatan, maka roh jahat bisa merasuki orang tersebut, sebab itu jangan beri kesempatan kepada roh jahat.

Bait Allah di sini menunjukkan pada pribadi orang percaya, jadi Tuhan tidak ingin tubuh ini dipakai hanya untuk penyembahan kepada berhala hanya demi pasangan hidup kita karena Tuhan tidak pernah memberi pasangan yang tidak baik bagi orang percaya dan berhala itu sangat jauh perbedaannya dan tidak akan mungkin bisa dipersatukan, sebab itu orang yang sudah hidup di dalam Kristus tidak diinjinkan mengambil pasangan dari mereka yang belum percaya atau yang masih menyembah berhala, karena Allah adalah Allah yang cemburu (Kej. 20:4).

Pasangan yang beda agama tidak akan mungkin bisa bersama-sama beribadah di bait Allah, melainkan yang satu akan menyembah kepada Allah yang ia percayai dan yang satu akan menyembah berhala sesuai dengan kepercayaannya.

\section{RANGKUMAN}

Kota Korintus merupakan kota yang maju dan terkenal sebagai kota yang makmur, sehingga banyak orang yang mengunjungi kota itu. Namun kota ini juga terkenal dengan penyembahan berhala dan kota cabul. Jemaat Korintus mulai berdiri saat Paulus datang ke sana memberitakan Injil kepada orang-orang di situ. Orang Yahudi menolak Paulus serta ajarannya, tetapi Paulus tidak menyerah begitu saja, melainkan Paulus mulai melayani orang-orang non-Yahudi, sehingga melalui orang-orang non-Yahudi ini pada akhirnya ada banyak orang yang percaya kepada Injil, karena itulah berdirinya jemaat di kota Korintus.

\footnotetext{
${ }^{55}$ Donald C. Stamps, Alkitab...,1927.
} 
Pasangan tidak seimbang ialah pasangan yang berbeda kepercayaan. Pasangan tidak seimbang dilarang berdasarkan keKristenan karena ada banyak hal yang tidak dapat mempersatukan pasangan yang tidak seimbang tersebut. Kebenaran yang diketahui oleh orang percaya ialah menjadi orang yang setia, menyatakan kebaikan seseorang dan kepercayaan kepada Kristus yang telah membenarkan orang percaya. Kedurhakan merupakan karakter manusia yang jahat dan orang yang melanggar aturan Allah. Sebab itu tidak akan mungkin mereka bisa bersatu.

Kristus adalah kudus, penyelamat umat manusia. Belial adalah Iblis yang hanya membawa manusia kepada jurang dan membawa orang percaya melanggar hukum Allah. Terang adalah karakter seseorang yang mampu menerangi orang lain, mampu mempengaruhi ke jalan yang benar. Gelap adalah mennjukan sikap buruk seseorang, jadi hubungan itu tidak akan bisa bersatu karena perbedaan yang sangat jauh serta terang jangan sampai dipengaruhi kegelapan.

Orang percaya adalah orang yang telah dibenarkan oleh Kristus dan menerima Kristus sebagai Tuhan juruselamat umat manusia, sehingga orang percaya menjadi orang yang setia dan selalu bersandar kepada Kristus. Orang tidak percaya adalah menunjukkan kepada orang yang bukan Kristen yang tidak mengakui Kristus sebagai Tuhan dan juruselamat umat manusia. Bait Allah adalah pusat tempat peribadahan kepada Allah. Bait Allah dalam hal ini ialah tempat suci dalam batin yaitu tubuh orang percaya adalah bait Allah yang kudus. Berhala adalah penyembahan kepada dewa-dewa yang disembah oleh orang yang tidak mengenal Allah.

Tuhan tidak pernah memberi pasangan yang salah kepada setiap umatNya dan Tuhan tidak pernah membiarkan seseorang itu menderita atau terus menerus dalam pergumulan pasangan, tetapi Tuhan pasti akan memberi yang terbaik bila kita tetap setia kepadaNya terlebih setia menanti jawaban doa kita yang dari Tuhan. Pasangan hidup bukan hanya sementara atau berjalan beberapa bulan, melainkan seumur hidup kita akan terus bersama dengan pasangan kita. Sebab itu penting pasangan yang seimbang atau yang seiman supaya dalam melakukan segala sesuatu atau memiliki visi yang sama, maka besar kemungkinan akan dapat masalah yang sangat besar atau yang akan menghalangi kita untuk melakukan apa yang sesungguhnya untuk memuliakan Tuhan. 
Pernikahan seimbang itu sangat penting khususnya dalam membina hubungan dengan Tuhan, dengan pasangan yang sama-sama Kristen, maka keluarga itu akan menjadi keluarga yang memuliakan Tuhan dan dalam menyelesaikan masalah akan menyelesaikannya sesuai dengan yang dikehendaki Tuhan, sehingga tidak mudah untuk menceraikan pasangannya karena Tuhan sendiri menegur menceraikan pasangan yang sudah diberkati Tuhan. Jadi menikah bukanlah hal yang mudah, punya tanggung jawab yang besar untuk membawa keluarga tersebut kepada kemuliaan Tuhan. 


\section{DAFTAR PUSTAKA}

Browning, W.R.F. (2011). Kamus Alkitab, Jakarta: BPK Gunung Mulia.

C Pfitzener, V. (2011). Kekuatan Dalam Kelemahan Ulasan Surat 2 Korintus, Jakarta: Gunung Mulia.

C. Halverson, Richard. (1967). The Living New Testament, Jakarta: Tyndale House.

C. Stamps, Donald. (2000). Alkitab Penuntun, Malang: Gandum Mas.

Drance, Jhon. (1996). Memahami Perjanjian Baru, Jakarta: Gunung Mulia.

F. Pfeiffer, Charles, dan Everett F. Harrison. (2001) The Wyclifee Bible Commnetary, Malang: Gandum Mas.

Guthrie, Donald. (1996). Tafsiran Alkitab Masa Kini 3 Matius-Wahyu, Jakarta: Yayasan Komunikasi Bina Kasih/OMF.

(2009). Pengantar Perjanjian Baru Vo. 2, Surabaya: Momentum.

Henry, Matthew. (2015). Tafsiran Surat Roma, 1 dan 2 Korintus, Surabaya: Momentum.

Henry, Matthew. (2015). Tafsiran Surat Roma, 1 dan 2 Korintus, Surabaya: Momentum.

L. Geisler, Norman. (2001). Etika Kristen Pilihan Dan Isu, Malang: Literatur SAAT.

L. Omanson, Roger dan John Ellington. (2013). Surat Paulus yang kedua kepada Jemaat di Korintus, Jakarta: LAI.

P. Spittler, Russell. (1977). Pertama Dan Kedua Korintus, Malang: Gandum Mas.

Ridderbos, Herman. (2008). Paulus Pemikiran Utama Theologinya, Surabaya: Momentum.

Susanto, Hasan. (2006). Perjanjian Interlinear Yunani-Indonesia Dan Konkordansi Perjanjian Baru (PBIK), Jakarta: LAI.

T. Brauch, Manfred. (1996). Ucapan Paulus Yang Sulit, Malang: SAAT.

Wesley Brill. (2003). Tafsiran Surat Korintus, Bandung: Kalam Hidup.

Y.H. Oman. (1975). Firman Allah Yang Hidup, Bandung: Kalam Hidup. 